Article

\title{
Decline in Performance of Biochemical Reactors for Sulphate Removal from Mine-Influenced Water is Accompanied by Changes in Organic Matter Characteristics and Microbial Population Composition
}

\author{
Parissa Mirjafari and Susan A. Baldwin * \\ Department of Chemical and Biological Engineering, University of British Columbia, Vancouver, BC V6T 1Z3, \\ Canada; parissa.mirjafari@gmail.com \\ * Correspondence: sbaldwin@mail.ubc.ca; Tel.: +1-604-822-1973 \\ Academic Editor: Alan Howard \\ Received: 1 February 2016; Accepted: 22 March 2016; Published: 30 March 2016
}

\begin{abstract}
Successful long-term bioremediation of mining-influenced water using complex organic matter and naturally-occurring microorganisms in sub-surface flow constructed wetlands requires a balance between easily and more slowly degrading material. This can be achieved by combining different types of organic materials. To provide guidance on what mixture combinations to use, information is needed on how the ratio of labile to recalcitrant components affects the degradation rate and the types of microbial populations supported. To investigate this, different ratios of wood and hay were used in up-flow column bioreactors treating selenium- and sulphate-containing synthetic mine-influenced water. The degradation rates of crude fibre components appeared to be similar regardless of the relative amounts of wood and hay. However, the nature of the degradation products might have differed in that those produced in the hay-rich bioreactors were more biodegradable and supported high sulphate-reduction rates. Microorganisms in the sulphate-reducing and cellulose-degrading inocula persisted in the bioreactors indicating that bio-augmentation was effective. There was a shift in microbial community composition over time suggesting that different microbial groups were involved in decomposition of more recalcitrant material. When dissolved organic carbon (DOC) was over-supplied, the relative abundance of sulphate-reducers was low even through high sulphate-reduction rates were achieved. As DOC diminished, sulphate-reducers become more prevalent and their relative abundance correlated with sulphate concentrations rather than sulphate-reduction rate.
\end{abstract}

Keywords: biochemical reactors; mine-influenced water; sulphate-reducing bacteria; microbial ecology; organic matter degradation; semi-passive bioremediation

\section{Introduction}

Mine-influenced water (MIW) contains constituents, such as selenium and sulphate, at levels that are potentially toxic to aquatic life [1-3] and needs to be treated before discharging to the receiving environment. One cost-effective method for remediating MIW is to use sub-surface flow constructed wetlands, commonly called biochemical reactors (BCRs), that contain waste organic material such as wood-chips, straw, hay, leaf compost, pulp mill biosolids, etc. [4-8]. These organic materials support many microorganisms including those that are important for metal removal, such as sulphate-reducers and metal-reducers [9-11]. The desired purpose in BCRs is slow degradation of the cellulosic constituents so as to provide a long-term supply of low molecular weight carbon 
sources such as fermentation products acetate, propionate, lactate, butyrate, alcohols, hydrogen and amines to fuel the microorganisms important for successful treatment [12-15]. Organic materials used in BCRs such as pine and spruce wood contain 67\%-73\% weight holocellulose [16]. These are more effective when combined with a digestible (labile) livestock feed such as grass hay containing 13\%-54\% weight neutral detergent-soluble material (a measure of the digestible (labile) components, such as starches, polysaccharides, pectin substances, crude protein $[17,18])$. Lignin, which is recalcitrant to biodegradation, comprises $27 \%-30 \%$ weight of pine and spruce wood, whereas it can be lower in grass hays [16]. Lignin can structurally block microbes from accessing holocellulose, making high lignin content material less biodegradable [19]. Some fungi can degrade ligin, however it is unknown if they are present in BCRs. One of the major challenges in deploying cellulosic-based bioreactors on a large scale at mine sites is the difficulty in predicting for how long the organic matrix will be effective. Many attempts have been made in the literature to correlate organic material characteristics, such as carbon to hydrogen ratio or dissolved organic carbon content, with effectiveness at sulphate-reduction and/or metal removal $[13,15,20]$. In previous studies, these variables were investigated in the early periods of operation before readily available compounds were depleted. Little or no work has been done to study how the organic materials in BCRs decompose over many months or years. The goal of this study was to measure the changes in organic material characteristics of mixtures of wood-chips, hay and cow manure over time in BCRs running for up to 450 days, and to see if particular changes in the organic material correlated with deviations from successful treatment.

Although the purpose of complex organic material in BCRs is to host microorganisms that provide biogeochemical conditions conducive to sulphate- and metal-reduction, the microbial communities in them are seldom monitored. Some previous attempts have been made to identify key functional groups and their activity [21]. The types of microbes introduced into BCRs at start-up influence their operation [22], with inocula previously acclimated to high-sulphate environments performing better than sources obtained from non-sulphate environments, such as livestock manure and anaerobic digesters [23]. Since the properties of organic materials change with age of the BCR, this might be expected to impact the types of microbes present. In this study, we used high throughput $16 \mathrm{~S}$ ribosomal deoxyribonucleic acid (16S rDNA) sequencing to chart microbial population shifts between the inoculum, start-up, early and late time points to see if the presence of metabolically important groups changes as the organic matter degrades. Additionally, organic material characteristics and microbial population shifts in columns using two different ratios of wood to hay were evaluated since they performed differently in terms of long-term sulphate reduction [24].

\section{Materials and Methods}

\subsection{Selection of Organic Materials and Preparation}

Due to costs incurred trucking materials to the mine site, locally available organic wastes are preferred for bioremediation. Forests in the mine area relevant to this study with an abundance of spruce, fir and balsam, provided cellulosic waste. Grass hay was a source of agricultural waste. Cow manure mixed with bedding material was available from a local stockyard and provided a source of microbial inocula, as well as some additional cellulosic materials. Wood pieces (50\% douglas fir, 30\% balsam fir, 20\% lodgepole pine and white spruce) were cut to $0.6 \mathrm{~cm}$ with a hammer mill. Hay was cut to $1.3 \mathrm{~cm}$ with a Wiley mill. A batch of manure plus bedding material was used without any size reduction. Manure came directly from the stockyard. Wood and hay were not green, but had been harvested with the past year and were not moldy. Thus, no pre-degradation of the organic material was apparent. All mixtures were homogenized for uniformity and combined in differing ratios for the laboratory column bioreactors. 


\subsection{Bioreactor Set-Up, Operation and Sampling}

Bioreactor set-up, operation and performance were described previously [24]. Briefly, six column bioreactors (inside diameter: $11.4 \mathrm{~cm}$, height: $50.8 \mathrm{~cm}$, working volume of $4.1 \mathrm{~L}$ ) were packed with two different combinations of organic materials: Wood-rich bioreactors with $40 \% \mathrm{dw}$ woodchips, $30 \% \mathrm{dw}$ hay and 30\%dw cow manure (BCR_W1, BCR_W2 and BCR_W3) and hay-rich bioreactors with 20\%dw woodchips, 50\%dw hay and 30\%dw cow manure (BCR_H1, BCR_H2 and BCR_H3) (dw stands for dry weight). In addition to organic material, crushed limestone was included (4\%dw). The porosity of each matrix was very similar: Average for the wood-rich BCRs was 0.69 with a standard deviation of 0.008 , and the average for the hay-rich BCRs was 0.68 with standard deviation of 0.008. During continuous flow, the influent flow rate was $0.29 \mathrm{~L} /$ day. Bioreactors were run for two periods of time in order to examine temporal changes in organic matter composition. One wood-rich bioreactor and duplicate hay-rich bioreactors were run for 159 days (referred to as early-sacrificed bioreactors) (Table 1). One hay-rich reactor ran for 430 days and two duplicate wood-rich BCRs were sacrificed after 455 days (the late-sacrificed bioreactors). A synthetic mine tailings water was used as influent with 500-600 mg/L sulphate and $15 \mu \mathrm{g} / \mathrm{L}$ selenium concentrations. Detailed composition of the influent was described previously [24]. At the end of the operating period, pore water chemistry variables were measured from ports distributed vertically from Port 8 ( $2 \mathrm{~cm}$ above the influent $)$ and at $2 \mathrm{~cm}$ intervals (Ports 7, 6, 5, 4 and 3) to the effluent at the top of the columns. The solids between ports were homogenized and the analyses described below were performed on triplicate samples from each section.

Table 1. Summary of the test conditions for the biochemical reactors (BCRs).

\begin{tabular}{cccccc}
\hline \multirow{2}{*}{ BCR } & \multicolumn{3}{c}{ Contents (\%dw) } & \multicolumn{2}{c}{ Length of Operation (Days) } \\
\cline { 2 - 6 } & Wood & Hay & Manure & Early & Late \\
\hline BCR_H1 & 20 & 50 & 30 & 159 & \\
BCR_H2 & 20 & 50 & 30 & 159 & 430 \\
BCR_H3 & 20 & 50 & 30 & & \\
BCR_W1 & 40 & 30 & 30 & 159 & 455 \\
BCR_W2 & 40 & 30 & 30 & & 455 \\
BCR_W2 & 40 & 30 & 30 & & \\
\hline
\end{tabular}

\subsection{Chemical Analyses}

At the time of sacrificing, pore water $\mathrm{pH}$ and oxidation-reduction potential (ORP) were measured using a 7200 (WTW, Weilham, Germany) meter and probes. Dissolved oxygen was measured using a Symphony SP50D meter (VWR). Sulphate and sulphide concentrations were measured using Standard Methods $4500-\mathrm{SO}_{4}{ }^{2-}$ and $4500-\mathrm{S}^{2-}$, respectively [25]. To characterize the organic mixtures into various degradable and recalcitrant portions, a sequential wash procedure was used (Figure 1). Two and

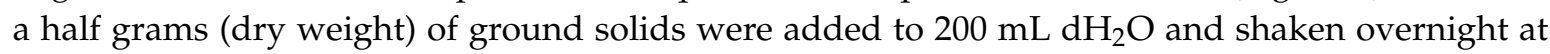
$200 \mathrm{rpm}$. The pore water (minus $0.45 \mu \mathrm{m}$ ) was analyzed for total dissolved organic carbon (DOC) (Shimadzu Total Organic Carbon analyzer). The dried residue was washed subsequently with a neutral detergent to separate more easily degradable material (neutral detergent-soluble (NDS)) from the crude fibre (neutral detergent fibre (NDF)) [26]. Neutral detergent contained $3.6 \mathrm{~g} \mathrm{NaOH}, 27 \mathrm{~g}$ sodium lauryl sulphate, $13.15 \mathrm{~g}$ Ethylenediaminetetraacetic acid, $6.13 \mathrm{~g}$ sodium borate decahydrate, $4.11 \mathrm{~g}$ disodium hydrogen phosphate and $9 \mathrm{~mL}$ triethylene glycol in $900 \mathrm{~mL}$ de-ionized water [27]. All chemicals were American Chemical Society grade purchased from Sigma-Aldrich (Oakville, ON, Canada). The ash contents of the water-wash residue and NDF were measured based on the change in mass after combustion at $500{ }^{\circ} \mathrm{C}$. Cellulose, hemicellulose and lignin content of the NDF was measured using methods in Reference [28]. 


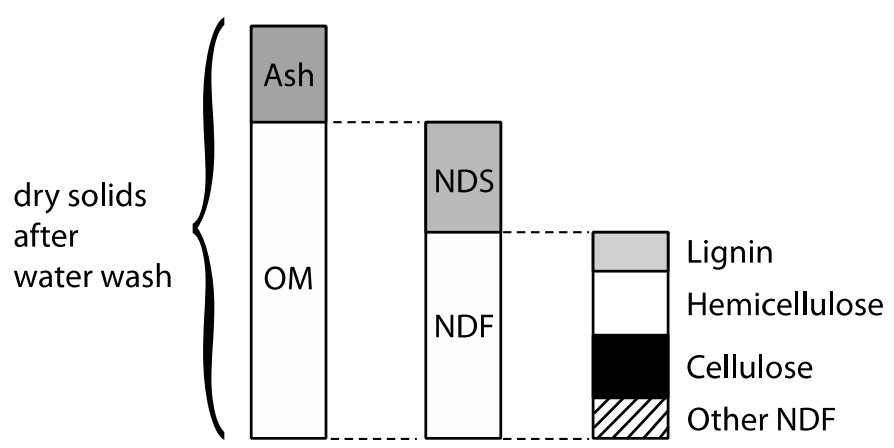

Figure 1. Cartoon depicting the fractions used to characterize the organic matter. $\mathrm{OM}=$ organic matter; NDS = neutral detergent soluble; $\mathrm{NDF}=$ neutral detergent fibre.

\subsection{Microbial Population Characterization}

Genomic DNA was extracted using the Power Soil Isolation Kit (MO BIO Laboratories Incorporation, Carlsbad, CA, USA). Isolated DNA was subjected to polymerase chain reaction (PCR) amplification of the V6 to V8 variable region of the 16S rDNA gene using primer sequences 926f (aaactYaaaKgaattgacgg) and 1392r (acgggcggtgtgtRc). For a $25 \mu \mathrm{L}$ PCR reaction, $12.5 \mu \mathrm{L}$ of $2 \times$ PCR Master Mix (Fermentas Canada Incorporation, Burlington, ON, USA), $10.5 \mu \mathrm{L}$ of nuclease-free water (Fermentas), $1 \mu \mathrm{L}$ of genomic DNA ( $2 \mathrm{ng}$ ) and $0.5 \mu \mathrm{L}$ of FLX Titanium amplicon primers 454T-RA and 454T-FB $(20 \mathrm{pmol} / \mu \mathrm{L})$ were used. PCR conditions were $95^{\circ} \mathrm{C}$ for $3 \mathrm{~min} ; 25$ cycles of $95^{\circ} \mathrm{C} ; 30 \mathrm{~s}, 56{ }^{\circ} \mathrm{C}$; $45 \mathrm{~s}, 72{ }^{\circ} \mathrm{C} ; 90 \mathrm{~s}, 72{ }^{\circ} \mathrm{C} ; 10 \mathrm{~min}$; final hold at $4{ }^{\circ} \mathrm{C}$. The PCR products were verified on a $1 \%$ agarose gel and sent to the MacMaster University Farncombe Metagenomics Center (Hamilton, ON, Canada) for Roche 454 titanium pyrotag sequencing. High quality pyrotag sequences (longer than 200 bases, with no more than 6 homopolymers and an average quality score greater than 25) were clustered into $\geqslant 90 \%$ (family-level equivalent) and $>94 \%$ (genus-level equivalent) sequence similarlity operational taxonomic units (OTUs) excluding chimeras using the software package usearch version 5.2.236 [29] in Qiime 1.8 [30]. The version 111 Silva reference set [31] was used for taxonomic classification of representative sequences. Singletons (OTUs represented by only one read only) were eliminated from the dataset.

\subsection{Statistical Methods}

Analysis of co-variance in R version 3.0.2 was used to test for statistically significant effects of wood to hay ratio, time of sacrificing and distance from the influent port (covariate) on organic material characteristics and pore water chemistry. Distance matrices comparing the microbial population compositions of the samples were determined using UniFrac [32], which is based on phylogenetic relationships, as well as Bray-Curtis dissimilarity, which is a commonly used index for comparing population structures [33]. Similarities between samples with respect to their microbial population compositions were visualized on three and two dimensional plots using principal co-ordination and detrended correspondence analysis (DCA) for UniFrac and Bray-Curtis, [34], respectively. To test for statistically significant effects on microbial population structure of organic material characteristics, a linear fit of DCA with DOC, NDF/NDS and lignin/hemicellulose ratio was performed using the envfit function in the R vegan package [35]. A heatmap of OTUs was produced with package pheatmap in $\mathrm{R}$ so as to visualize how microbial taxa were distributed throughout the samples. Samples were clustered according to their similarities in microbial population composition using Euclidean distance and complete hierarchical clustering (dist and hclust in R). Taxa were grouped according to their co-occurrence determined using pair-wise Pearson Correlation of their relative abundances (read count transformed by log to the base 2). 


\section{Results and Discussion}

\subsection{Sulphate-Reduction Rate within the BCRs}

Over the short term (first 159 days of operation), all reactors performed similarly in that sulphate and selenium were removed to below detection limit concentrations [24]. Thereafter, only the hay-rich bioreactors achieved the target sulphate concentration of less than $100 \mathrm{mg} / \mathrm{L}$. Whereas, the wood-rich bioreactors experienced variable performance [24]. All bioreactors regardless of their organic matter composition or length of operation were able to maintain environmental conditions within the pore water suitable for sulphate-reducing bacteria (i.e., $\mathrm{pH}$ : 6.4 to 6.8 , DO: 0.1 to $0.5 \mathrm{mg} / \mathrm{L}$ and ORP: -375 to $-312 \mathrm{mV}$ ) [24]. At the time of sacrificing, sulphate concentrations within the BCRs as a function of distance above the inlet, corresponding to increasing hydraulic retention time, revealed that sulphate was more rapidly reduced in the hay-rich than in the wood-rich matrix (Figure 2). Most sulphate-reduction occurred at the bottom of the columns, between the influent and Port 8 .
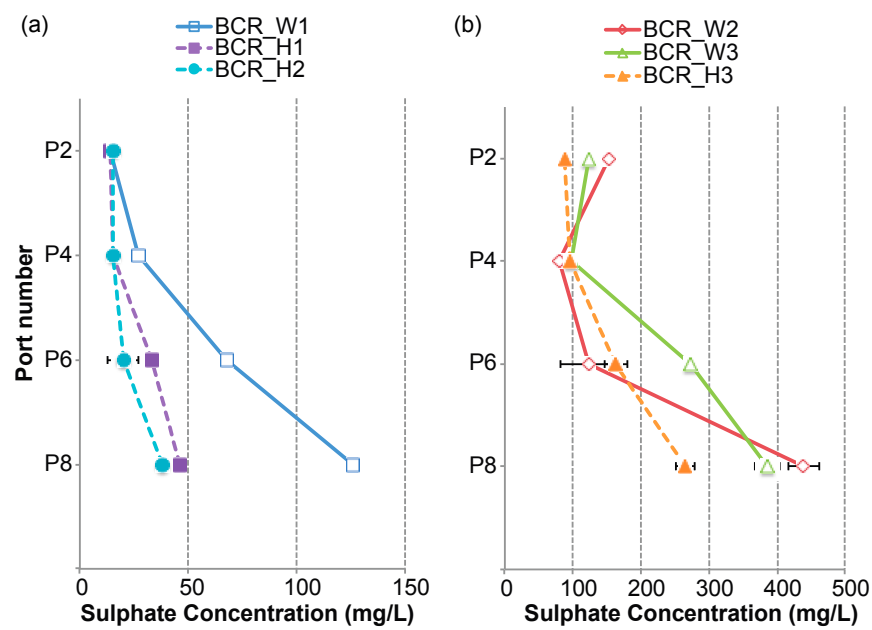

Figure 2. Sulphate concentrations measured in the pore water from different ports for the (a) earlyand (b) late-sacrificed BCRs.

Sulphate concentrations decreased from $586 \mathrm{mg} / \mathrm{L}$ in the influent to an average of $42 \mathrm{mg} / \mathrm{L}$ at Port 8 (HRT of approximately 2 days) in the duplicate early-sacrificed hay-rich bioreactors, whereas in the wood-rich bioreactor 2 to 6 days HRT was needed for sulphate to reach below the required level of $100 \mathrm{mg} / \mathrm{L}$ (Figure 2a). The highest sulphate-reduction rate measured in the hay-rich column, $2.8 \mathrm{mM}-\mathrm{SO}_{4}{ }^{2-} /$ day, is far less than rates achieved in bioreactors fed defined carbon sources (e.g., $1.4 \mathrm{mM}-\mathrm{SO}_{4}{ }^{2-} / \mathrm{h}$ was measured in a sulphate-reducing bioreactor fed ethanol, glycerol, lactate and citrate [36]), but is within the same range as rates measured for permeable reactive barriers (1-3 $\mathrm{mM}_{-} \mathrm{SO}_{4}{ }^{2-}$ / day [10]). Permeable reactive barriers are similar to BCRs in that they also use cellulosic substrates as carbon sources for sulphate-reduction over the long-term. Low sulphate-reduction rates when using complex organic materials are because supply of the low molecular weight carbon sources preferred by sulphate-reducers is limited by the rate of hydrolysis of long-chain carbohydrates. By the time the late-sacrificed reactors were analysed, the sulphate-reduction rate within all bioreactors had declined substantially (Figure $2 b$ ). In all reactors, a residence time up to Port 4 (HRT of approximately 10 days) was needed to reduce sulphate from $580 / 615 \mathrm{mg} / \mathrm{L}$ (hay-/wood-rich influent concentrations, respectively) to less than $100 \mathrm{mg} / \mathrm{L}$. Still the sulphate reduction rate within the hay-rich bioreactor, near the influent ( $\left.1.7 \mathrm{mM}-\mathrm{SO}_{4}{ }^{2-} / \mathrm{day}\right)$, was higher than that observed for the duplicate wood-rich bioreactors $\left(1.1 \mathrm{mM}^{-\mathrm{SO}_{4}}{ }^{2-} /\right.$ day). Only in the hay-rich column did the sulphate concentration continue to decrease towards the effluent. Whereas, in both wood-rich bioreactors, there was an increase in sulphate concentration from Port 4 to Port 2 , 
which contributed to these reactors not meeting the $100 \mathrm{mg} / \mathrm{L}$ sulphate concentration target. Taken together, these results show that in the early days of operation a hay-rich organic matrix confers a significant advantage over a wood-rich matrix in terms of sulphate-reduction rate. However, later (after 430-455 days of operation) sulphate-reduction rates declined such that approximately 5 times the HRT was needed to achieve the same performance. Short-term tests of organic materials for BCRs are likely to be overly optimistic in prediction of treatment performance. Thus, these types of bioreactors must be overdesigned initially if they are to meet regulatory requirements over the long term.

The differences in performance between the hay- and wood-rich and short- and long-term bioreactors can be attributed to several factors, discussed subsequently. Possible factors affecting their longevity include changes in the chemical environment, the rate of biodegradation of the organic material, changes in the nature of the bioavailable substrates and possible shifts in microbial population structure.

\subsection{Sulphide Concentrations within the BCRs}

Production of sulphide from sulphate-reduction can result in inhibition of microbial growth due to the toxicity of $\mathrm{H}_{2} \mathrm{~S}$ [37]. Sulphide concentrations measured immediately upon sacrificing of the columns did not exceed $100 \mathrm{mg} / \mathrm{L}$ (Figure S1), which is well below the concentrations shown previously to be inhibitory [38]. The presence of sulphide is indicative of active sulphate-reduction. In the early-sacrificed hay-rich bioreactors, very little sulphide was detected above Port 8 since most sulphate was reduced prior to Port 8. In the other bioreactors sulphate-reduction was taking place throughout the length of the columns. It was possible that some sulphide might have been re-oxidized to sulphate near the effluent port as suggested by the decrease in sulphide and corresponding increase in sulphate above Port 4 (Figures S1b and $2 \mathrm{~b}$, respectively). This was one likely contribution to failure of the long-term wood-rich bioreactors to meet treatment requirements. A sink for excess sulphide is required, thus dissolved iron was included in the feed water. Even though the reactor columns were completely filled with matrix and water, oxygen may have infiltrated through the effluent port, where samples were removed regularly during operation. It is possible that in the field it would be difficult to completely eliminate oxygen from these types of bioreactors, especially near the effluent, thus supplemental iron might be required if there are insufficient concentrations of metal cations in the feed water. Metal cations react with sulphide to form metal sulphide precipitates. Additionally, it was possible that some sulphide was re-oxidized to elemental sulphur, although this was not confirmed.

\subsection{Supply of Dissolved Organic Carbon}

Supply of DOC was not limited in the early-sacrificed columns, and concentrations in the pore water of the hay-rich bioreactors were much higher, reaching up to $1552 \mathrm{mg} / \mathrm{L}$, than those in the wood-rich columns where the highest measured DOC value was $267 \mathrm{mg} / \mathrm{L}$ (Figure 3a). This might explain the differences seen in sulphate-reduction rates between the two matrices, since this indicated that there was an over-supply of carbon sources suitable for sulphate-reduction in the hay-rich BCRs. This verifies the notion that having extra hay in the organic matrix provides more easily-degradable compounds. Organic acids such as acetate and propionate, which are products of fermentation and favoured by sulphate-reducers as carbon sources [39,40], were detected in the pore water of the early sacrificed hay-rich bioreactors only (Figure 4). 


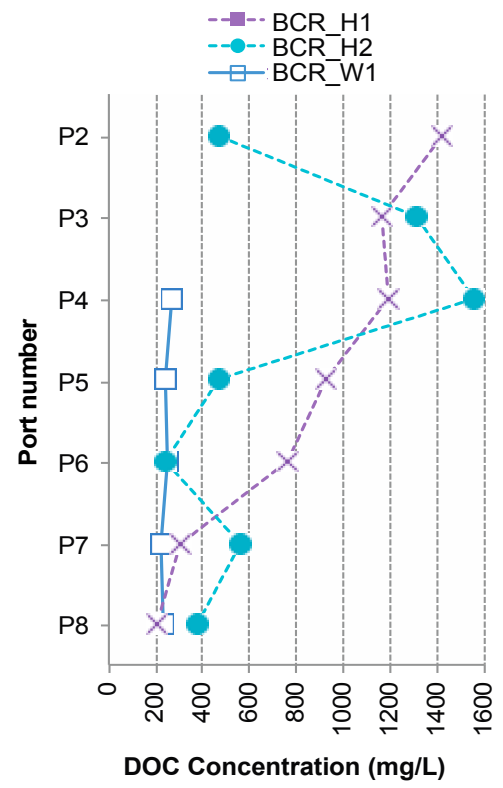

(a)

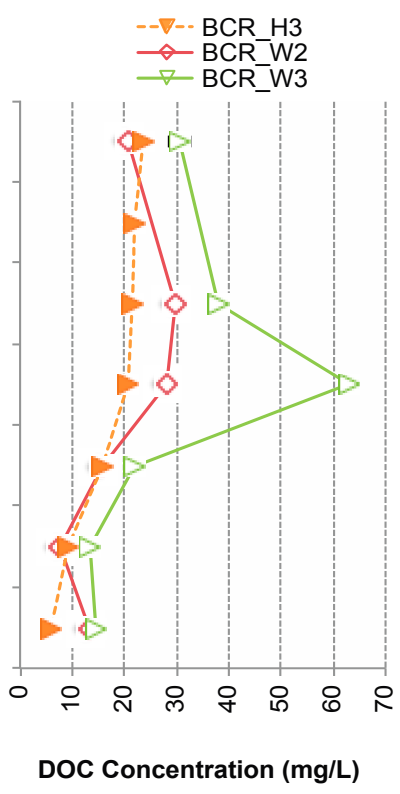

(b)

Figure 3. Dissolved organic carbon (DOC) concentrations measured in the pore water from different ports. (a) Early-sacrificed BCRs; (b) Late-sacrificed BCRs.

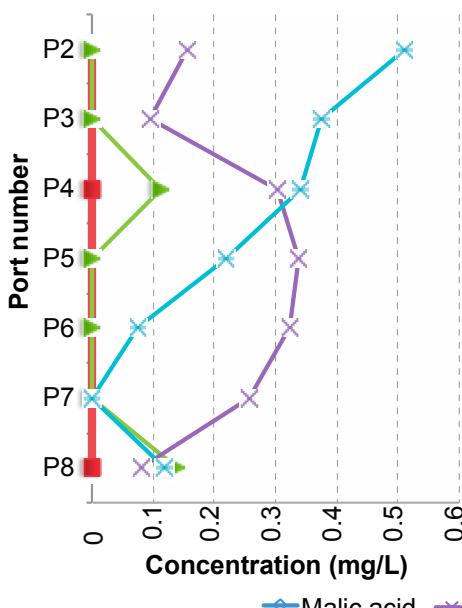

- Lactate $*$ Acetate

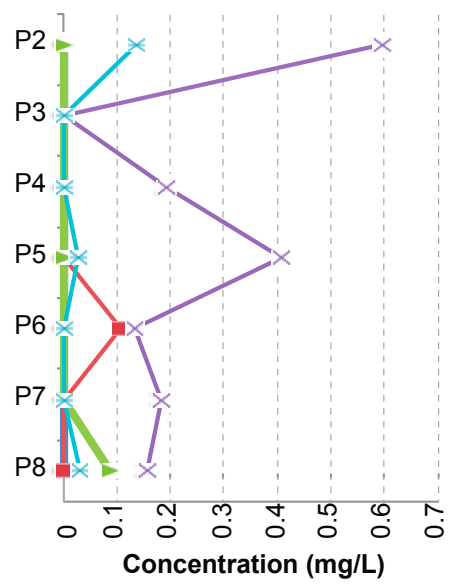

Formate $\longleftarrow$

(b)

Figure 4. Concentrations of organic acids detected in the pore water from different ports. No organic acids were detected in the wood-rich or the longer running hay-rich BCRs. (a) Hay-rich BCR 1 (early-sacrificed); (b) Hay-rich BCR 2 (early-sacrificed).

Much less DOC was measured in the pore water from the longer running bioreactors, but conversely, there were slightly higher amounts in the wood-rich than in the hay-rich bioreactors (Figure 3b). Dissolved organic carbon concentrations in most columns increased with HRT, as expected if the rate of DOC supply minus DOC used was constant. But, this was not uniform throughout the columns, and from Ports 5 or 4 upwards DOC concentrations started to decrease with HRT in one of the early-sacrificed hay-rich and both late-sacrificed wood-rich bioreactors. Greater rates of sulphate-reduction in the lower sections of the columns might have contributed to increased DOC consumption at those locations, but it was not clear what contributed to DOC decrease in the upper parts of the columns. The organic acid profiles in each of the duplicate early-sacrificed 
hay-rich bioreactors in Figure 4 were different. In one column there was a net production of acetate, which was not seen in the duplicate column. Propionate concentrations reach a maximum around Port 5. Thereafter there was a net consumption of propionate. One explanation might be that propionate limits the rate of its production through product inhibition, which has been reported for anaerobic digestion [41]. After propionate drops to low concentrations at Port 3, propionate-producing fermenters appear to reinvigorate as suggested by the increases in propionate concentration towards the effluent port.

\subsection{Organic Matter Degradation}

The rate of supply of the dissolved organic compounds needed by sulphate-reducers is thought to be controlled by the rate of hydrolysis of the complex polymeric compounds in the organic matter. In an attempt to measure how quickly the OM was degraded it was divided into crude fractions that broadly measure labile and recalcitrant components. Overall, the ash contents of both hay- and wood-rich matrices were greater in the late-sacrificed bioreactors than in the early-sacrificed ones ( $p<0.05$ for the wood-rich, and $p<0.001$ for the hay-rich columns) (Figure 5). Limestone and mineral matter within the organics contributed to the ash content of the original material. Increase of ash over time was expected due to organic matter mineralization and the accumulation of precipitates, such as FeS. Based on a sulphur mass balance and the assumption that sulphide unaccounted for ends up as FeS, masses of FeS precipitates accumulating in the BCRs were estimated (Table S1) The increase in average ash content from $26.8 \% \pm 4.5 \%$ to $51.5 \% \pm 9.9 \%$ in the hay-rich bioreactors was greater than that measured in the wood-rich bioreactors $(25.0 \% \pm 8.6 \%$ to $34.5 \% \pm 16.9 \%)$ (Figure 5 ). Analogous ash contents between the hay- and wood-rich early-sacrificed bioreactors suggest that organic matter degradation might have been similar over that period of operation. Whereas, over the long-term, organic matter in the hay-rich bioreactors appeared to be degrading 2-3 times as fast as that in the wood-rich bioreactors.

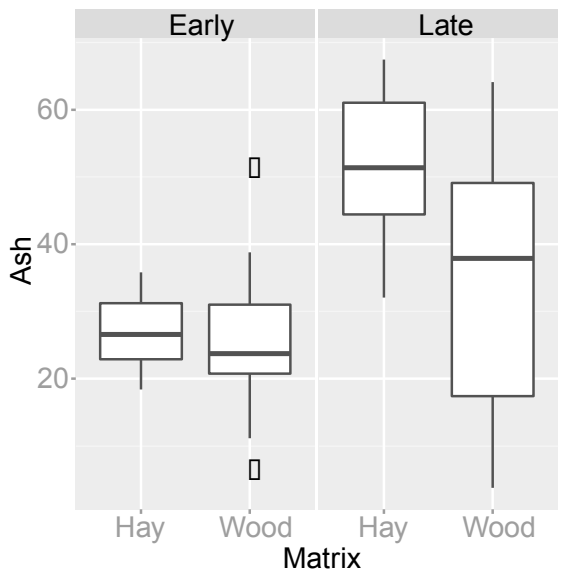

Figure 5. Ash content (as a percentage of the total mass-dry weight) of samples from the hay- and wood-rich BCRs at the early- and late-sacrificed time points. Data presented as Tukey box-and-whisker plots where the box represents upper and lower quartiles, the heavy horizontal line the mean, the whiskers the maximum and minimum values minus outliers (dots). Outliers are values outside 1.5 times of the upper and lower quartiles, respectively.

Although there was no statistically significant difference in ash content with height above the influent for the early-sacrificed reactors, there was a statistically significant increase in ash content towards the bottom (near the influent) of the late-sacrificed bioreactors ( $p<0.001$ for the wood-and $p<0.05$ for the hay-rich columns) (Figure S2a,b). Since most sulphate-reduction occurred closer to the inlet, more iron sulphide precipitates were expected to form there. This might have contributed to the higher ash contents near the influent. 
The neutral detergent wash removes the more easily digestible compounds such as starches, polysaccharides, pectin substances, and crude protein (the NDS fraction, also sometimes referred to as extractives). The remaining NDF represents recalcitrant chemical compounds such as lignin and cellulose. It was expected that the NDS fraction would decrease faster over time and the amount of NDF would decrease more slowly. This seemed to be the case for the hay-rich bioreactors as the NDF/NDS ratio increased over time $(p<0.001)$ (Figures 6 and S3). In contrast, the NDF/NDS ratio decreased with time in the wood-rich bioreactors. Possibly there are differences in the types of chemical compounds that comprise the NDS fractions in the wood- and hay-rich matrices, respectively. Conversion of the NDF into NDS material might have been occurring in the wood-rich bioreactors, with the resulting degradation products comprising the NDS fraction not as degradable as those generated from NDF hydrolysis in the hay-rich BCRs. The higher DOC concentrations seen in the hay-rich columns corroborates the notion of hay crude fibre decomposing more readily.

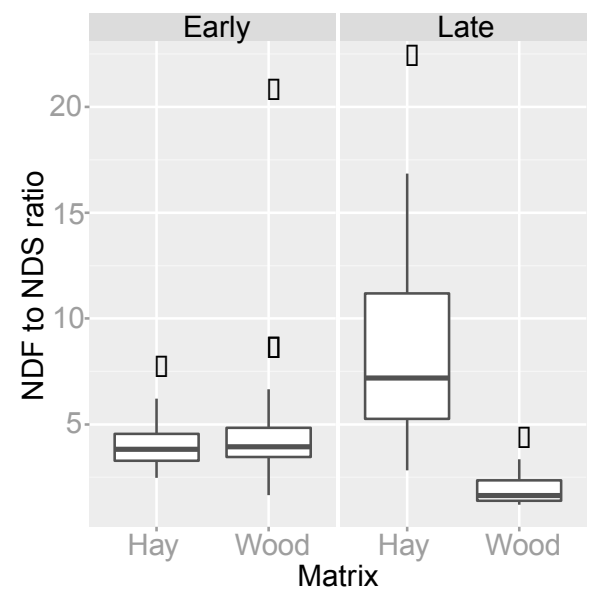

Figure 6. Neutral detergent fibre (NDF) to neutral detergent soluble (NDS) fraction ratio of samples from the hay- and wood-rich BCRs at the early- and late-sacrificed time points.

The reason for using cellulosic material for these bioreactors is so that there is a slow, but steady, supply of organic carbon for sulphate-reducing bacteria. After $\sim 430$ days of operation, for all bioreactors, the lowest sulphate concentration was very close to the target of $100 \mathrm{mg} / \mathrm{L}$. In an attempt to predict longevity of the crude fibre carbon sources, the amounts of hemicellulose and cellulose consumed and remaining were estimated. The decrease in cellulose fraction was greater and statistically significant $(p<0.001)$ for the hay-rich bioreactors compared to the wood-rich bioreactors (Figure 7). For both matrices, hemicellulose fraction decrease was statistically significantly $(p<0.001)$ and also greater for the hay-rich matrix. As expected, the increase in lignin fraction was more pronounced for the hay-rich versus wood-rich bioreactors. Changes in the fractions of holocellulose components (combined hemicellulose and cellulose) alone do not allow estimates of their rate of decomposition. If it is assumed that lignin was not biodegraded during the experiment and that its amount in the bioreactors remained constant, then the degree of NDF reduction can be estimated. Lignin has a very complex molecular structure due to cross linkages of phenyl propane units [42], which makes it very hard to break and biodegrade. In addition, biodegradation of lignin is an oxidative reaction that would be limited in anaerobic environments due to the fact that extracellular enzymes need oxygen to produce $\mathrm{H}_{2} \mathrm{O}_{2}$, which breaks down lignin. It was calculated, based on this assumption, that the NDF in the wood-rich bioreactors decreased by $18.2(11.8) \%$ and $40.3(6.7) \%$ in the earlyand late-sacrificed columns, respectively. These estimates were similar for the hay-rich bioreactors: $17.0(5.3) \%$ and $42.5(4.3) \%$ for the early- and late-sacrificed bioreactors, respectively. The crude fibre fractions of both matrices appear to be degrading at similar rates. If these rates are extrapolated into 
the future, the supply of NDF is predicted to last for another approximately 2 years, suggesting that the overall lifetime of these reactors is about $3 \frac{11 / 4}{4}$ years.

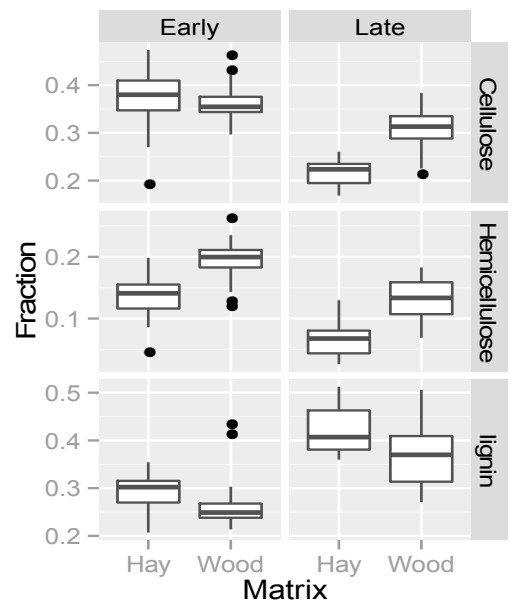

Figure 7. Fractions of lignin, hemicellulose and cellulose in samples from the hay- and wood-rich BCRs at the early- and late-sacrificed time points.

As the NDF degrades over time, the nature of the degradation products and their bioavailability might change. The nature of bioavailable substrates might be reflected in the kinds of microorganisms present. Thus, the microbial community structure of the bioreactors was compared over time to see if any shifts were detected and whether any inferences could be drawn regarding the nature of bioavailable substrates.

\subsection{Microbial Communities Supported by the Hay- and Wood-Rich BCRs and Their Evolution over Time}

Previous studies used molecular methods to identify sulphate-reducing and organic matter degrading taxonomic groups in BCRs [22,43]. These previous methods were insufficient to capture the diversity of microbial species expected in anaerobic, organic-rich biomes. Little is known about which taxonomic groups are present in these types of bioreactors, and it is necessary to know how the population structure correlates with environmental conditions, operational parameters and performance metrics. A sufficient body of knowledge on shifts in microbial population structure in bioreactors is needed before metagenomic analyses can be useful for practical bioreactor monitoring. In this study, microbial communities were surveyed to see which taxonomic groups present in the inocula persisted in the bioreactors, and to test if microbial population structure changed over time as the organic matter degraded with concomitant changes in substrate types and availability.

A total of 52 samples were used for microbial population analysis including sulphate-reducing (SRB) and cellulose-degrading (CDB) cultures, inocula, time zero, early- and late-sacrificed bioreactor samples. After quality screening, 412,052 SSU rDNA sequence reads were clustered into $84,190 \%$ sequence similarity (equivalent to family-level) operational taxonomic units (OTUs) or 1,546,394\% sequence similarity (equivalent to genus-level) OTUs with 3710 to 16,962 reads per sample. Rarefaction performed with several diversity indices: phylogenetic diversity based on the whole tree [30] and Shannon [44], revealed that the sulphate-reducing bacteria cultures were the least diverse, whereas manure and one of the cellulose-degrading bacteria cultures were the most diverse. There were no statistically significant correlations of the diversity indices with length of operation of the columns or between wood-rich and hay-rich columns (Figures S4 and S5).

The microbial population structures of the BCRs shifted over time. The time zero, early- and late-sacrificed bioreactor microbial populations clustered separately (Figure 8). Within each time point, the wood- and hay-rich bioreactor microbial populations grouped separately, suggesting that the different mixtures contained slightly different relative abundances of the represented taxonomic 
groups. Clustering of the sample microbial populations according to time first and then matrix (hay or wood) was confirmed using un-weighted UniFrac distances (principal co-ordinate diagram shown in Figure S6) and hclust (heatmap presented in Figure S7) The method UniFrac calculates distances based on phylogenetic information [32]. The function hclust in R performs complete linkage hierarchical clustering [45].

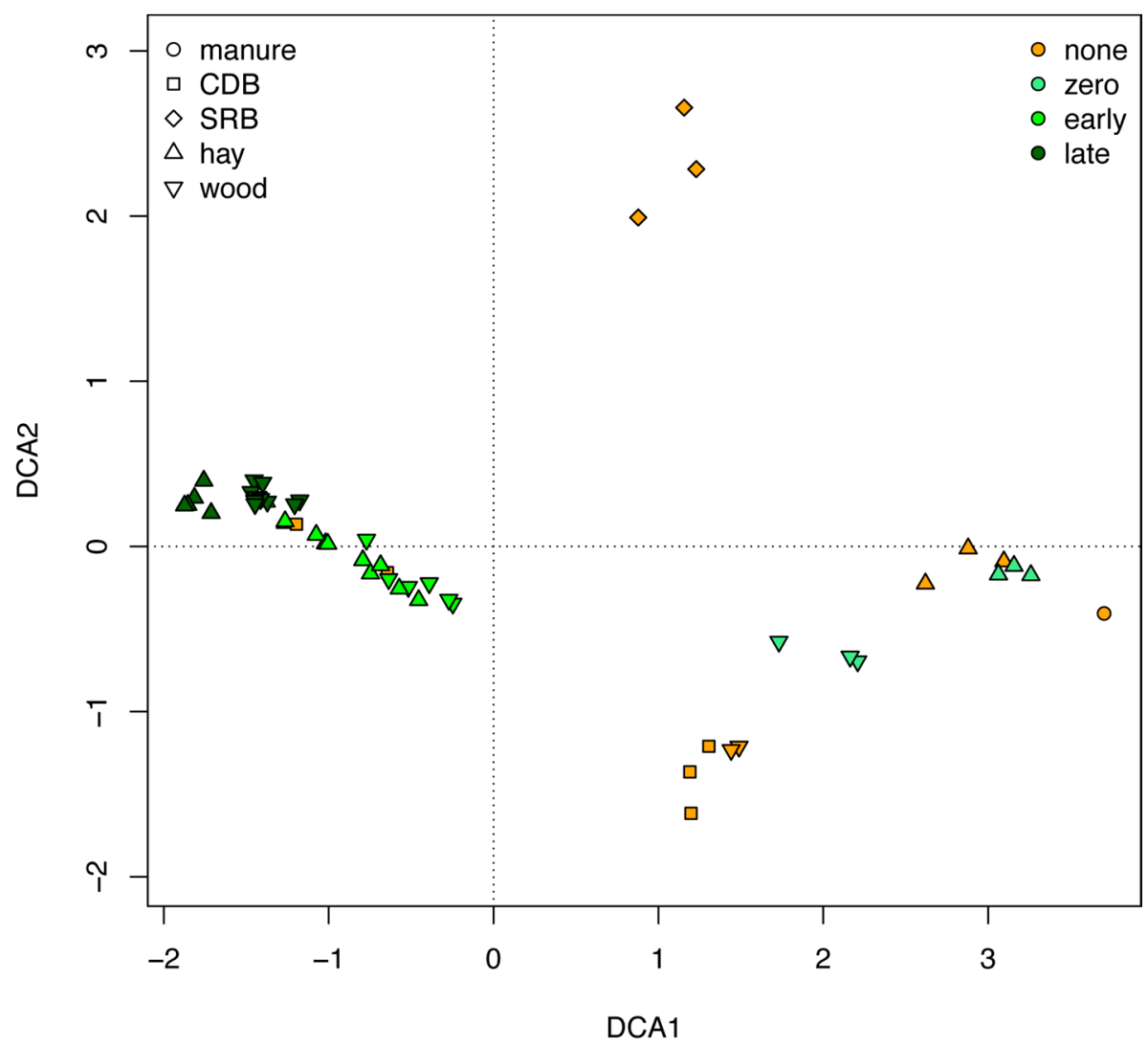

Figure 8. Detrended correspondence analysis (DCA) of Bray-Curtis dissimilarities for $90 \%$ similarity cut-off operational taxonomic unit (OTU) read counts in the cultures (sulphate-reducing bacteria (SRB), cellulose-degrading bacteria (CDB) and manure) inocula, time zero, early- and late-sacrificed BCR samples. Colours depict time points with "none" refering to the laboratory cultures used to prepare the incula. Time zero samples are in light green, early-sacrificed samples in green and late-sacrificed samples in dark green.

The laboratory SRB and CDB cultures used to prepare the BCR inocula contained many taxonomic groups that were important for the BCRs (Figure 9), whereas the predominant taxonomic groups in the manure did not proliferate in the BCRs. Manure was added to the organic mixtures since it is often included in BCRs due to the notion that it provides needed organic matter decomposing bacteria. In this instance this was not the case, and using pre-fermented cultures grown on the same hay and wood materials as used in the BCRs were effective as inocula. Thus, for practitioners there might be no benefit to transporting manure to the BCR site. Additionally, avoiding the use of manure will prevent the introduction of pathogens into the environment, as they are often present in livestock fecal material [46]. Manure might have provided some carbonaceous material that was useful for supporting microbial growth. 


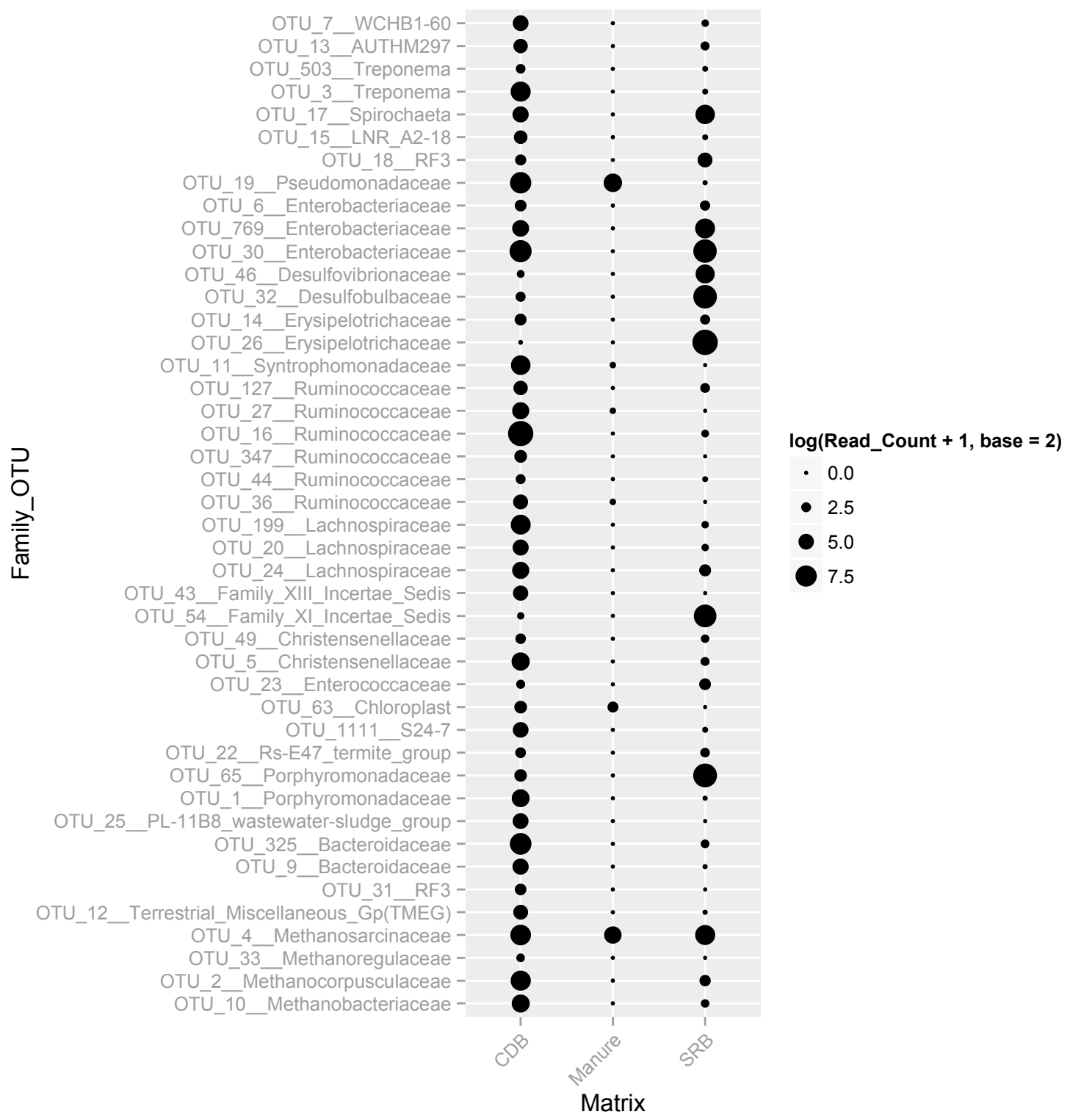

Figure 9. Read counts in the celluose-degrading (CDB) and sulphate-reducing bacteria (SRB) lab cultures and manure, of the high relative abundance (in the BCRs) operational taxonomic units (OTUs) ( $90 \%$ similarity cut-off, comprising at least greater than $0.5 \%$ of the total read count). Taxonomic assignment of each OTU is written next to the OTU ID number. The size of the bubble is proportional to the read count of that OTU (log to the base 2 transformed). Values are averages of all the samples in each category. Several samples were analyzed for each matrix.

The taxonomic groups from the $\mathrm{CDB}$ cultures that proliferated in the BCRs were predominantly members of the Bacteriodetes and Firmicutes phyla that are associated with anaerobic organic matter degradation. Seventy percent of the Bacteroidaceae-related genus-level OTUs were classified as Bacteroides. Species of this genus are known to use complex organic matter degradation products, such as starch and xylan, and are predominant members of herbivore gut microbiota [47]. Some Bacteroides species can degrade cellulose [48]. Genera present in the BCRs within the Porphyromonadaceae family (such as Dysgonomonas, Paludibacter, Parabacteroides, and Porphyromonas) are related to gut-associated cultured species known to degrade cellulose [49] and other plant-derived polymers [50], as well as ferment sugars to propionate [51]. A wider variety of Firmicutes-related taxa were present. Many (50\%) were not classified at the genus-level and little can be deduced as to their function in the bioreactors. 
Ruminococcus-related genus-level OTUs comprised $40 \%$ of the Ruminococcaceae and representatives of this genus are highly prevalent intestinal microbiota involved in anaerobic plant polysaccharide degradation [47].

The SRB cultures were the source of Desulfovibrionaceae and Desulfobulbaceae-related sulphate-reducers. Although the latter family was more prevalent in the cultures, the former proliferated in the BCRs. The CDB cultures, manure and SRB cultures also introduced methanogens into the BCRs.

The time zero samples consisted of mixtures of the inocula, which were prepared using the CDB and SRB cultures, and fresh hay- or wood-rich organic material. Differences between the hayand wood-rich matrices were already apparent in the time zero samples (Figure 10). The microbial communities evolved over time in the bioreactors with notable increases in presence of Spirochaetes-, Bacteroidetes- Firmicutes- and methanogen-related OTUs, and decrease of Proteobacteria-related taxa. In the late-sacrificed bioreactors, there was a decline in the relative abundance of Firmicutes- and Bacteroideaceae-related taxa, and increase in Spirochaetes- and methanogen-related taxa, especially in the wood-rich BCRs. Decline of the important organic matter degraders coincided with reduction in dissolved organic carbon and increase in the NDF/NDS fraction (Figure S8). This shift in microbial population structure might be a sign of declining availability of readily digestible organic substrates. Proliferation of methanogens and their putative syntrophs (Spirochaetes) suggested that they might have been competing for organic substrates needed by sulphate-reducers. Both of these factors would likely contribute to deterioration in performance of the bioreactors. Relative abundance of certain environmental groups, such as the Terrestrial Miscellaneous Euryarchaeota Group (TMEG), RF3, WCHB1-60 and AUTHM297 increased in the late-sacrificed bioreactors. Since no cultured representatives exist for these groups nothing is known about their putative functions. They might possess unique metabolisms that enable them to survive in nutrient constrained environments, such as highly degraded organic matter.

There was no clear trend in microbial community structure with position in the columns, except for the sulphate-reducers. Desulfovibrio- and Desulfobulbus-related OTUs that were the most prevalent of the sulphate-reducing bacteria (Figures S9 and S10), had increased read counts towards the bottom of the columns (Figure 11). Their relative abundance correlated with sulphate concentration. In the early-sacrificed columns, especially those containing the hay-rich mixture, where the supply of readily available (dissolved) organic compounds is non-limiting, sulphate-reducers were present only near the influent. The early-sacrificed wood-rich columns were less efficient at supplying dissolved carbon sources and sulphate-reducers were found all the way up the column. In the late-sacrificed columns, when the supply of readily available carbon sources was limiting, sulphate-reducers were more prevalent throughout all columns. It is important to note that SRB taxa relative abundance did not correlate with sulphate-reduction rates, but rather with sulphate concentration. It has been discovered in other sites that low numbers of sulphate-reducers can sustain remarkably high rates of sulphate reduction [52,53]. Presence of sulphate-reducing bacteria indicates that the environment inside the bioreactors was suitable for these organisms, but sulphate-reduction rates correlate with the rate of supply of readily available carbon sources provided by organic matter degraders. Decline of important organic matter degraders within the Firmicutes and Bacteroidetes phyla, might indicate that there was a decrease in availability of their preferred substrates, possibly restricting the supply of organic carbon to sulphate reducers. Greater proliferation of organic matter degraders in the early-sacrificed hay-rich bioreactors and the presence of higher concentrations of DOC meant that having more hay than wood conferred an advantage on the bioreactors in sustaining higher sulphate-reduction rates. However, concomitant decline in organic matter degraders in both the late-sacrificed hay- and wood-rich bioreactors indicated that longevity of successful performance might be similarly restricted in both matrices. 


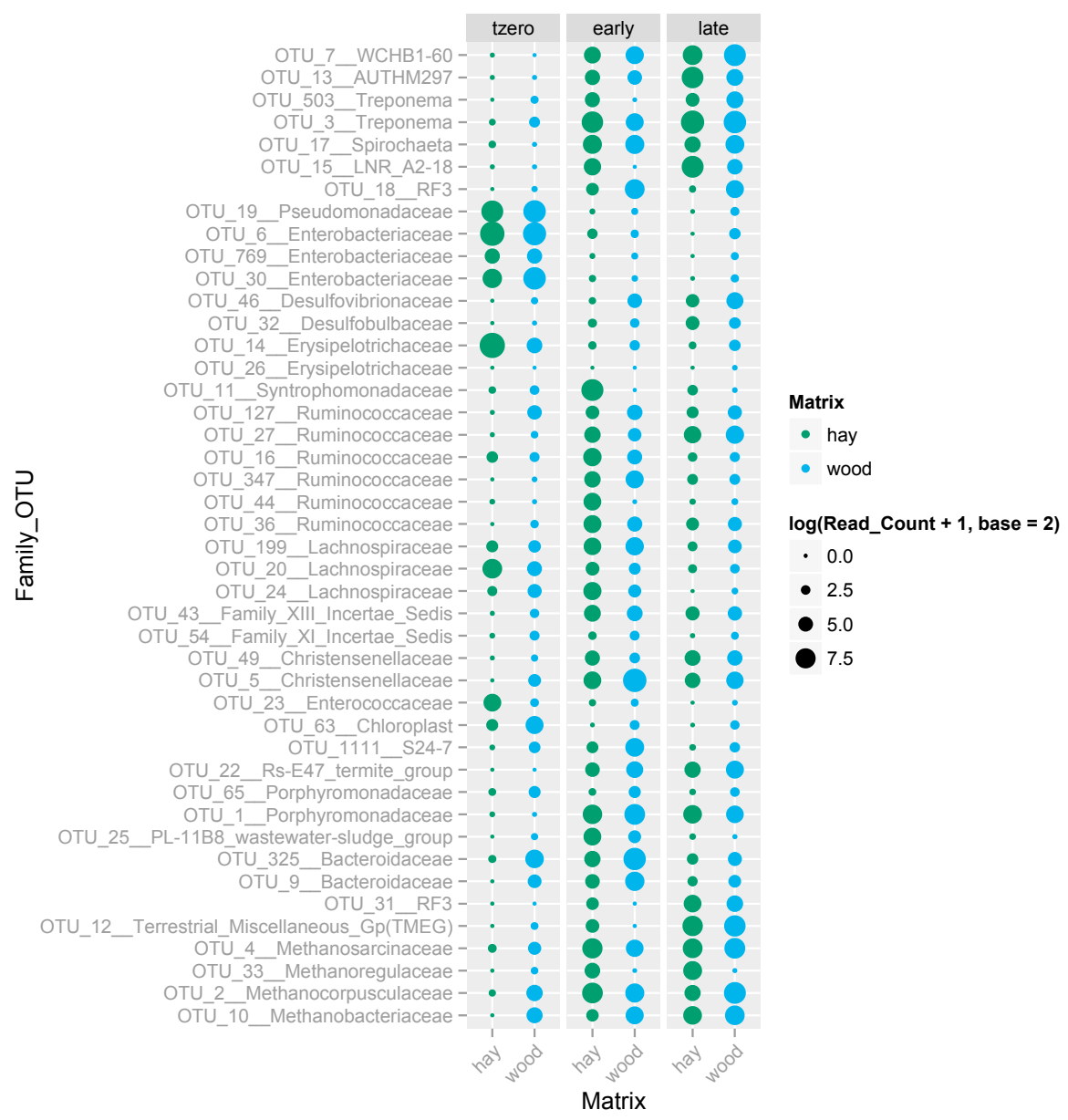

Figure 10. Read counts of the high relative abundance operational taxonomic units (OTUs) (90\% similarity cut-off, comprising at least greater than $0.5 \%$ of the total read count) in the hay- and wood-rich BCRs at time zero and in the early- and late-sacrificed BCRs. Taxonomic assignment of each OTU is written next to the OTU ID number. The size of the bubble is proportional to the read count of that OTU (log to the base 2 transformed).

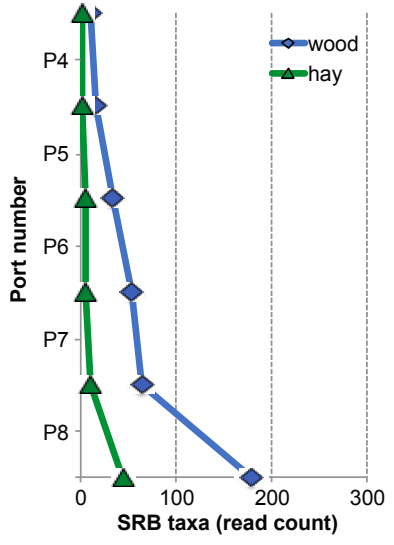

(a)

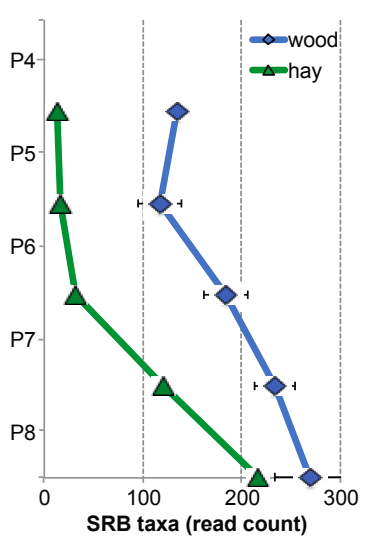

(b)

Figure 11. Total read counts of operational taxonomic units (OTUs) (94\% similarity cut-off) assigned to known sulphate-reducing bacteria (SRB) taxa. P8 refers to the reactor section from the inlet to port 8; P78 refers to the reactor section from port 8 to port 7, and so on. (a) early-sacrificed BCRs; (b) late-sacrificed BCRs. 


\section{Conclusions}

Sulphate-reduction rates measured during the early operation of these bioreactors were not representative of the rates sustainable over the longer term, which were three to five times slower. Thus, in testing and designing of passive remediation systems based on cellulosic materials this must be taken into account.

Although the degradation rates of crude fibre in two different wood-hay mixtures were similar, the products produced in the hay-rich mixture appear to be more biodegradable providing higher concentrations of dissolved organic carbon to fuel higher sulphate-reduction rates. It is recommended that higher amounts of hay are needed to achieve better sulphate-reduction rates.

Sulphate-reduction rates correlated with organic matter availability and not high sulphate concentrations nor greater relative abundance of sulphate-reducing bacteria.

Using sulphate-reducing and cellulose-degrading cultures for inoculum preparation was useful in that the taxonomic groups introduced were those that were most prevalent in the bioreactors. In contrast, manure did not provide many microbial taxa that became important in the bioreactors. Bio-augmentation of suitable cultures is recommended when constructing BCRs and manure may not be needed.

There was a decline in relative abundance of important organic matter degrading taxa from the early- to late-sacrificed bioreactors signalling the increasing recalcitrance of the remaining organic matter.

Supplementary Materials: The following are available online at www.mdpi.com/2073-4441/8/4/124/s1.

Acknowledgments: Mount Polley Mine, Teck Mining Company, NatureWorks Remediation Corporation, Genome British Columbia and the Natural Sciences and Engineering Research Council of Canada are acknowledged for funding through an Applied Genomics Innovation Program grant 108ROC and a Collaborative Research and Development Project grant 364108-07 to S.A. Baldwin. Undergraduate and CO-OP students Resza Boenawan, Leila Saeedi, Melissa Liu, Miao Jun Su are thanked for their help with the many chemical analyses.

Author Contributions: S.B. conceived of the study. P.M. performed all the laboratory work and data analysis. S.B. contributed to the data analysis. Both P.M. and S.B. contributed to writing the manuscript.

Conflicts of Interest: The authors declare no conflict of interest.

\section{Abbreviations}

The following abbreviations are used in this manuscript:

\begin{tabular}{ll}
\hline BCR & Biochemical reactor \\
CDB & Cellulose degrading bacteria \\
DCA & Detrended corresponsence analysis \\
DO & Dissolved oxygen \\
DOC & Dissolved organic carbon \\
DNA & Deoxyribonucleic acid \\
H & Hay \\
HRT & Hydraulic retention time \\
MIW & Mine influenced water \\
NDF & Neutral detergent fibre \\
NDS & Neutral detergent soluble \\
OM & Organic matter \\
PCR & Polymerase chain reaction \\
ORP & Oxidation-reduction potential \\
OUT & Operational taxonomic unit \\
SRB & Sulphate-reducing bacteria \\
TOC & Total organic carbon \\
W & Wood \\
\hline
\end{tabular}




\section{References}

1. Outridge, P.M.; Scheuhammer, A.M.; Fox, G.A.; Braune, B.M.; White, L.M.; Gregorich, L.J.; Keddy, C. An Assessment of the Potential Hazards of Environmental Selenium for Canadian Water Birds. Environ. Rev. 1999, 7, 81-96. [CrossRef]

2. Lemly, A.D. Teratogenic effects of selenium in natural populations of freshwater fish. Ecotoxicol. Environ. Saf. 1993, 26, 181-204. [CrossRef] [PubMed]

3. Elphick, J.R.; Davies, M.; Gilron, G.; Canaria, E.C.; Lo, B.; Bailey, H.C. An aquatic toxicological evaluation of sulfate: the case for considering hardness as a modifying factor in setting water quality guidelines. Environ. Toxicol. Chem. 2011, 30, 247-253. [CrossRef] [PubMed]

4. Johnson, D. Recent Developments in Microbiological Approaches for Securing Mine Wastes and for Recovering Metals from Mine Waters. Minerals 2014, 4, 279-292. [CrossRef]

5. Blumenstein, E.P.; Gusek, J.J. Designing a biochemical reactor for selenium and thallium removal, from bench scale testing through pilot construction. In Hydrometallurgy 2008-Proceedings of the Sixth International Symposium, Phoenix, AZ, USA, 17-20 August 2008; Young, C.A., Taylor, P.R., Anderson, C.G., Choi, Y.C.A., Eds.; Society for Mining, Metallurgy, Exploration Inc.: Phoenix, AZ, USA, 2008; pp. 117-129.

6. Baldwin, S.A.; Hodaly, A.H. Selenium Uptake by a Coal Mine Wetland Sediment. Water Qual. Res. J. Can. 2003, 38, 483-497.

7. Zinck, J.; Griffith, W. Review of Mine Drainage Treatment and Sludge Management Operations; Report CANMET-MMSL 10-058(CR); CANMET Mining and Mineral Sciences Laboratory, Natural Resources Canada: Ottawa, ON, Canada, 2013.

8. Mattes, A.; Evans, L.J.; Gould, D.W.; Duncan, W.F.A.; Glasauer, S. The long term operation of a biologically based treatment system that removes As, $\mathrm{S}$ and $\mathrm{Zn}$ from industrial (smelter operation) landfill seepage. Appl. Geochem. Sources Transp. Fate Trace Toxic Elem. Environ. 2011, 26, 1886-1896.

9. Schmidtova, J.; Baldwin, S.A. Correlation of bacterial communities supported by different organic materials with sulfate reduction in metal-rich landfill leachate. Water Res. 2011, 45, 1115-1128. [CrossRef] [PubMed]

10. Logan, M.V.; Reardon, K.F.; Figueroa, L.A.; McLain, J.E.; Ahmann, D.M. Microbial community activities during establishment, performance, and decline of bench-scale passive treatment systems for mine drainage. Water Res. 2005, 39, 4537-4551. [CrossRef] [PubMed]

11. Pereyra, L.; Hiibel, S. Detection and quantification of functional genes of cellulose-degrading, fermentative, and sulfate-reducing bacteria and methanogenic archaea. Appl. Environ. Microbiol. 2010, 76, 2192-2202. [CrossRef] [PubMed]

12. Roman, H.; Madikane, M.; Pletschke, B.I.; Rose, P.D. The Degradation of Lignocellulose in a Chemically and Biologically Generated Sulphidic. Environ. Bioresour. Technol. 2008, 99, 2333-2339. [CrossRef] [PubMed]

13. Costa, M.C.; Martins, M.; Jesus, C.; Duarte, J.C. Treatment of Acid Mine Drainage by Sulphate-reducing Bacteria Using Low Cost Matrices. Water Air Soil Pollut. 2007, 189, 149-162. [CrossRef]

14. Lindsay, M.B.J.; Blowes, D.W.; Condon, P.D.; Ptacek, C.J. Organic Carbon Amendments for Passive in situ Treatment of Mine Drainage: Field Experiments. Appl. Geochem. 2011, 26, 1169-1183. [CrossRef]

15. Zagury, G.J.; Kulnieks, V.I.; Neculita, C.M. Characterization and reactivity assessment of organic substrates for sulphate-reducing bacteria in acid mine drainage treatment. Chemosphere 2006, 64, 944-954. [CrossRef] [PubMed]

16. Sjöström, E. Wood Chemistry: Fundamentals and Applications, 2nd ed.; Academic Press: San Diego, CA, USA, 2013.

17. Hall, M.B.; Pell, A.N.; Chase, L.E. Characteristics of neutral detergent-soluble fiber fermentation by mixed ruminal microbes. Anim. Feed Sci. Technol. 1998, 70, 23-39. [CrossRef]

18. Schofield, P.; Pell, A.N. Measurement and kinetic analysis of the neutral detergent-soluble carbohydrate fraction of legumes and grasses. J. Anim. Sci. 2014, 73, 3455-3463.

19. Van der Weijde, T.; Alvim Kamei, C.L.; Torres, A.F.; Vermerris, W.; Dolstra, O.; Visser, R.G.; Trindade, L.M. The potential of C4 grasses for cellulosic biofuel production. Front. Plant Sci. 2013, 4, 107. [CrossRef] [PubMed]

20. Waybrant, K.R.; Blowes, D.W.; Ptacek, C.J. Selection of Reactive Mixtures for Use in Permeable Reactive Walls for Treatment of Mine Drainage. Environ. Sci. Technol. 1998, 32, 1972-1979. [CrossRef] 
21. Pereyra, L.P.; Hiibel, S.R.; Perrault, E.M.; Reardon, K.F.; Pruden, A. Effect of bioaugmentation and biostimulation on sulfate-reducing column startup captured by functional gene profiling. FEMS Microbiol. Ecol. 2012, 82, 135-147. [CrossRef] [PubMed]

22. Pruden, A.; Messner, N.; Pereyra, L.; Hanson, R.E.; Hiibel, S.R.; Reardon, K.F. The Effect of Inoculum on the Performance of Sulfate-Reducing Columns Treating Heavy Metal Contaminated Water. Water Res. 2007, 41, 904-914. [CrossRef] [PubMed]

23. Lefèvre, E.; Pereyra, L.P.; Hiibel, S.R.; Perrault, E.M.; De Long, S.K.; Reardon, K.F.; Pruden, A. Molecular assessment of the sensitivity of sulfate-reducing microbial communities remediating mine drainage to aerobic stress. Water Res. 2013, 47, 5316-5325. [CrossRef] [PubMed]

24. Mirjafari, P.; Baldwin, S.A. Performance of sulphate- and selenium-reducing biochemical reactors using different ratios of labile to recalcitrant organic materials. Water Sci. Technol. 2015, 72, 875. [CrossRef] [PubMed]

25. Eaton, A.D.; Clesceri, L.S.; Rice, E.W.; Greenberg, A.E. Standard Methods for the Examination of Water and Wastewater; American Public Health Association: Washington, DC, USA, 2005.

26. Vansoest, P.J.; Robertson, J.B.; Lewis, B.A. Methods for Dietary Fiber, Neutral Detergent Fiber, and Nonstarch Polysaccharides in Relation to Animal Nutrition. J. Dairy Sci. 1991, 74, 3583-3597. [CrossRef]

27. Hall, M.B. Neutral-Detergent Soluble Carbohydrates-Nutritional Relevance And Analysis; Laboratory Manual; Institute of Food and Agricultural Sciences, University of Florida: Gainesville, FL, USA, 2000; Bulletin 339.

28. Wieder, R.K.; Starr, S.T. Quantitative Determination of Organic Fractions in Highly Organic, Sphagnum Peat Soils. Commun. Soil Sci. Plant Anal. 1998, 29, 847-857. [CrossRef]

29. Edgar, R.C. Search and clustering orders of magnitude faster than BLAST. Bioinformatics 2010, 26, $2460-2461$. [CrossRef] [PubMed]

30. Caporaso, J.G.; Kuczynski, J.; Stombaugh, J.; Bittinger, K.; Bushman, F.D.; Costello, E.K.; Fierer, N.; Pena, A.G.; Goodrich, J.K.; Gordon, J.I.; et al. QIIME allows analysis of high-throughput community sequencing data. Nat. Methods 2010, 7, 335-336. [CrossRef] [PubMed]

31. Quast, C.; Pruesse, E.; Yilmaz, P.; Gerken, J.; Schweer, T.; Yarza, P.; Peplies, J.; Glöckner, F.O. The SILVA ribosomal RNA gene database project: Improved data processing and web-based tools. Nucleic Acids Res. 2013, 41, D590-D596. [CrossRef] [PubMed]

32. Lozupone, C.; Knight, R. UniFrac: A new phylogenetic method for comparing microbial communities. Appl. Environ. Microbiol. 2005, 71, 8228-8235. [CrossRef] [PubMed]

33. Washington, H.G. Diversity, biotic and similarity indices. Water Res. 1984, 18, 653-694. [CrossRef]

34. Hill, M.O.; Gauch, H.G. Detrended Correspondence Analysis: An Improved Ordination Technique. Vegetatio 1980, 42, 47-58. [CrossRef]

35. Oksanen, J.; Guillaume Blanchet, F.; Kindt, R.; Legendre, P.; Minchin, P.R.; O’Hara, R.B.; Simpson, G.L.; Solymos, P.; Stevens, M.H.H.; Wagner, H. Vegan: Community Ecology Package. R package version 2.3-3, 2016. Available online: https:/ /CRAN.R-project.org/package=vegan (accessed on 29 March 2016).

36. Bratkova, S.; Koumanova, B.; Beschkov, V. Biological treatment of mining wastewaters by fixed-bed bioreactors at high organic loading. Bioresour. Technol. 2013, 137, 409-413. [CrossRef] [PubMed]

37. O'Flaherty, V.; Mahony, T.; O'Kennedy, R.; Colleran, E. Effect of pH on growth kinetics and sulphide toxicity thresholds of a range of methanogenic, syntrophic and sulphate-reducing bacteria. Process Biochem. 1998, 33, 555-569. [CrossRef]

38. Reis, M.A.; Almeida, J.S.; Lemos, P.C.; Carrondo, M.J. Effect of hydrogen sulfide on growth of sulfate reducing bacteria. Biotechnol. Bioeng. 1992, 40, 593-600. [CrossRef] [PubMed]

39. Elferink, S.; Luppens, S.; Marcelis, C.; Stams, A. Kinetics of acetate oxidation by two sulfate reducers isolated from anaerobic granular sludge. Appl. Environ. Microbiol. 1998, 64, 2301-2303.

40. Muyzer, G.; Stams, A.J.M. The ecology and biotechnology of sulphate-reducing bacteria. Nat. Rev. Microbiol. 2008, 6, 441-454. [CrossRef] [PubMed]

41. Mösche, M.; Jördening, H.-J. Comparison of different models of substrate and product inhibition in anaerobic digestion. Water Res. 1999, 33, 2545-2554. [CrossRef]

42. Fengel, D.; Wegener, G. Wood: Chemistry, Ultrastructure, Reactions; Walter de Gruyter: New York, NY, USA, 1989. 
43. Pereyra, L.P.; Hiibel, S.R.; Pruden, A.; Reardon, K.F. Comparison of microbial community composition and activity in sulfate-reducing batch systems remediating mine drainage. Biotechnol. Bioeng. 2008, 101, 702-713. [CrossRef] [PubMed]

44. Shannon, C.E. A Mathematical Theory of Communication. Bell. Syst. Tech. J. 1948, 27, 379-423. [CrossRef]

45. Legendre, P.; Legendre, L. Numerical Ecology, 3rd ed.; Elsevier: Amsterdam, The Netherlands, 2012.

46. Cotruvo, J.A.; Dufour, A.; Rees, G.; Bartram, J.; Carr, R.; Cliver, D.O.; Craun, G.F.; Fayer, R.; Gannon, V.P.J. Waterborne Zoonoses: Identification, Causes, and Control; World Heath Organization (WHO), IWA Publishing: London, UK, 2004.

47. Flint, H.J.; Bayer, E.A.; Rincon, M.T.; Lamed, R.; White, B.A. Polysaccharide utilization by gut bacteria: Potential for new insights from genomic analysis. Nat. Rev. Microbiol. 2008, 6, 121-131. [CrossRef] [PubMed]

48. Giuliano, C.; Khan, A.W. Cellulase and Sugar Formation by Bacteroides cellulosolvens, a Newly Isolated Cellulolytic Anaerobe. Appl. Environ. Microbiol. 1984, 48, 446-448. [PubMed]

49. Mewis, K.; Armstrong, Z.; Song, Y.C.; Baldwin, S.A.; Withers, S.G.; Hallam, S.J. Biomining active cellulases from a mining bioremediation system. J. Biotechnol. 2013, 167, 462-471. [CrossRef] [PubMed]

50. Wexler, H.M. Bacteroides: The good, the bad, and the nitty-gritty. Clin. Microbiol. Rev. 2007, $20,593-621$. [CrossRef] [PubMed]

51. Ueki, A.; Akasaka, H.; Suzuki, D.; Ueki, K. Paludibacter Propionicigenes gen. nov., sp nov., A Novel Strictly Anaerobic, Gram-Negative, Propionate-Producing Bacterium Isolated from Plant Residue in Irrigated Rice-Field Soil in Japan. Int. J. Syst. Evol. Microbiol. 2006, 56, 39-44. [CrossRef] [PubMed]

52. Dillon, J.G.; Fishbain, S.; Miller, S.R.; Bebout, B.M.; Habicht, K.S.; Webb, S.M.; Stahl, D.A. High rates of sulfate reduction in a low-sulfate hot spring microbial mat are driven by a low level of diversity of sulfate-respiring microorganisms. Appl. Environ. Microbiol. 2007, 73, 5218-5226. [CrossRef] [PubMed]

53. Pester, M.; Bittner, N.; Deevong, P.; Wagner, M.; Loy, A. A "rare biosphere" microorganism contributes to sulfate reduction in a peatland. ISME J. 2010, 4, 1591-1602. [CrossRef] [PubMed]

(C) 2016 by the authors; licensee MDPI, Basel, Switzerland. This article is an open access article distributed under the terms and conditions of the Creative Commons by Attribution (CC-BY) license (http:/ / creativecommons.org/licenses/by/4.0/). 